\title{
Social tenants' health: Evaluating the effectiveness of landlord interventions
}

\section{Paul Cheshire' ${ }^{1}$ Stephen Gibbons ${ }^{1} \&$ Jemma Mouland ${ }^{2}$}

\author{
This version October 2017
}

${ }^{1}$ Spatial Economics Research Centre and Department of Geography and Environment, London School of Economics and Political Science, London, UK.

${ }^{2}$ Former Head of Research and Policy, Family Mosaic, London, UK.

Corresponding author: Paul Cheshire, Dept. of Geography \& Environment, London School of Economics, Houghton St, London WC2A 2AE, U.K., fax +44 (0)20 7955 7412, phone: +44 (0)20 7955 7586, p.cheshire@lse.ac.uk.

Acknowledgements: The study was initiated and funded by Family Mosaic. Ethical approval was obtained through the London School of Economics ethics board. The Big Lottery Fund provided funding for the Friends Who Do Lunch initiative which was run as part of this pilot project. The authors are responsible for all errors and interpretation.

Key Words: randomised control trial; social housing; health interventions

Word count: 4405

Reference count: 13 


\begin{abstract}
Background The NHS scores well internationally on access to health care. But access has been measured on methods likely to undersample the more disadvantaged. Social landlords have access to more disadvantaged groups and may be able to improve health outcomes for their tenants and reduce their NHS usage by simple interventions.
\end{abstract}

Method A randomised controlled trial of 547 London social housing 'general needs' tenants over 50 years of age. Participants were given a health assessment then split into a control group or one of two treated groups. Following early assessment 25 participants had to be withdrawn to receive intensive treatment because of currently untreated major health problems. Participants were followed up over 18 months and changes in health outcomes and NHS usage measured.

Results Compared to the control the most intensively treated group showed non-significant improvements on health outcomes but a significant reduction in NHS resource use, on conventional costings worth some $£ 760$ per person. All 25 participants transferred to the most intensively treated group after their early health assessments showed improvement on all health outcomes at final assessment but these improvements were not statistically significant.

Conclusions Drawing a sample from disadvantaged but not the most seriously disadvantaged groups in London revealed 4.5 percent of the population to have very serious untreated health problems. The reason for lack of treatment was mainly non-registration with a GP or psychiatric issues. Simple interventions to a targeted group were found to produce significant reductions in NHS usage and other, albeit non-significant, health benefits. 


\section{Introduction}

The UK fares well in international surveys of access to health care [1] but still there is overwhelming evidence that poor health is associated with low income at an individual level.[2,3] Since basic economics implies that people with low incomes live in neighbourhoods with low-cost housing, these neighbourhoods inevitably have concentrations of people with a range of income-related disadvantages such as poor health, disabilities and lower educational attainment.[4] The Marmot Review [5] focused attention on such inequalities highlighting, for example, that people living in the poorest neighbourhoods in England will on average die seven years earlier than people living in the richest, and will on average spend 17 more years disabled.

This sorting of low income people into low cost housing is an international phenomenon [4] and suggests a role for providers of low cost housing to be involved in community health interventions. Historically, some philanthropic providers of social housing played this role: in the $19^{\text {th }}$ Century, the Peabody Trust ensured its tenants were vaccinated against smallpox.[6] Although in some countries such as Sweden [7] there is recent experience of these types of health intervention, there are only the vestiges of such a tradition in Britain or in many other OECD countries. In Britain registered Social Landlords house some of the most vulnerable citizens, and have a unique level of access to people who may not be engaged with health and other public services through existing channels. There is to date no evidence of which we are aware that such landlords could play a part in interventions effectively to promote improved health and wellbeing for their tenants. This study therefore aimed to fill this gap and, using a randomised controlled trial, test the hypothesis that through the utilisation of their landlord status to gain access to tenants, higher rates of engagement could be obtained with vulnerable people to improve their health and wellbeing.

The study focused on providing interventions for a group of people aged over-50 who lived in socially provided 'general needs accommodation' in London. An older demographic was selected since this group has the highest usage of NHS services and greatest health needs.

The key objective of this study was therefore:

- To test whether a social landlord, Family Mosaic, could improve the health and wellbeing of their over-50s general-needs tenant population with simple interventions.

The two services that were tested were:

1. A signposting service from the Neighbourhood Manager (the local manager responsible for a group of properties).

2. An intensive handholding service from a specialised team of health and wellbeing support workers.

In the rest of this paper we first discuss the trial design and the interventions for each of the two treated groups. We then discuss the health outcomes measured, the sample and the 
process of randomisation. The setup of the study is presented in Section 3 and in Section 4 we analyse the differences in the outcomes between the control and the two treated groups. In the final section we discuss the implications of the study.

\section{Methods}

\subsection{Trial Design}

A parallel three-arm randomised control trial was used, with an even-split random allocation across three groups: a control group (Group 1), a lightly-treated, 'signposted' group (Group 2) and an intensively treated 'handholding' group (Group 3). Details of the interventions are described below.

The first stage for all participants before randomisation was a base-line health check and collection of basic personal information. This showed that while only a handful were not registered with any GP, 17.9 percent were receiving no health related support at all. Only three of these people reported their health as 'very good' and many had severe and chronic issues such as emphysema, diabetes or hypertension. At this initial stage some participants were identified as having conditions which posed an immediate threat to their health and wellbeing, even their life. This meant they could not risk being placed in either the control or signposted groups so they were removed from the main study and placed in a sub-group $3 b$. Fifteen individuals were identified at the first assessment prior to randomisation. A further 10 either were identified at, or before the subsequent 9 month assessment point. So in total 25 people - some 4.5 percent of the participants - were immediately identified on the basis of a simple health assessment as suffering serious, often life threatening conditions for which they were receiving no treatment. People in Group $3 b$ were directed to their GP or hospital for treatment where necessary, but otherwise received the same services as those in Group 3. This non-randomly selected group is excluded from Group 3 in the main analysis, but their outcomes are discussed separately in Section 3.7.

\subsection{Participants}

The eligibility criteria for participants were set as:

- Aged 50 or more

- Living in a General Needs Family Mosaic property: that is ordinary social housing not housing aimed at the elderly or physically disabled. Participants did not have to be the main tenant.

- Living in the borough of Hackney, Islington, Hammersmith and Fulham, Kensington and Chelsea or Haringey

Data on eligibility was gathered from Family Mosaic's central database. Data on secondary household members is less comprehensive and so on occasions other eligible household members were referred via the lead tenants that we approached. There was no restriction on multiple household members taking part in the study, although none did. 


\subsection{Interventions}

As noted above two types of interventions were tested in this study:

The 'signposting' intervention (Group 2) was provided by the Neighbourhood Manager, the social housing provider's frontline staff member responsible for managing the properties and tenancies within a given patch. The intervention entailed the Neighbourhood Manager reviewing the assessments carried out (see Section 2.4) and identifying any needs from these. They would then refer participants to a suite of interventions available (see Appendix 1). Subsequent contact would then be on a quarterly basis either through a phone call or visit.

The 'handholding' intervention (Group 3) was delivered by a newly formed in-house team of Health and Wellbeing Support Workers. Support workers reviewed the baseline assessment and identified any potential needs or areas for intervention (see Appendix 2). Whilst the focus of the interventions was similar to those received by Group 2 participants, the means of accessing the services differed. Participants were actively supported to engage with the relevant interventions, with support in doing so ranging from helping to make travel arrangements to actually accompanying participants to sessions to build their confidence in attending. Participants were visited and their needs assessed by their support worker on anything from a weekly to monthly basis depending on their level of need.

\subsection{Outcomes}

For the purposes of the analysis there were two assessments: the baseline assessment and a follow up at the end after 18 months. For internal purposes there was an additional assessment after 9 months. It was at this stage that an additional 10 participants were identified who were withdrawn from the main study and placed into Group $3 b^{1}$.

The baseline assessments were carried out in participants' homes face-to-face interviews. Due to problems in arranging meetings or getting access and the need to maintain participant goodwill, some of the 9 and 18 month assessments were carried out by phone or post. On all occasions where there was an ambiguity in self-completed assessments a support worker followed this up with the participant. The majority of the assessments were carried out by in-house trained health assessors.

The primary outcomes assessed are shown in Table 1. Other, secondary outcomes, looked at the impact of services on enabling people to better manage their back conditions and arthritis and on the consequences of fuel poverty. Results for these outcomes are not reported here.

\footnotetext{
${ }^{1}$ Two each from the Control Group and Group 3 and 6 from Group 2.
} 
Table 1: Primary outcome measures

\begin{tabular}{|c|c|c|}
\hline Outcome group & Measures & Scale \\
\hline $\begin{array}{l}\text { Self-reported health } \\
\text { outcomes }\end{array}$ & $\begin{array}{l}\text { General health rating } \\
\text { Average health rating (asked at } \\
\text { beginning and end of survey, average } \\
\text { of these taken) }\end{array}$ & $\begin{array}{l}5 \text { point Likert scale } \\
0-10 \text { numeric scale }\end{array}$ \\
\hline Mental wellbeing & $\begin{array}{l}\text { ONS Wellbeing measuret } \\
\text { Short Warwick Edinburgh Mental } \\
\text { Wellbeing Scale(SWEMWBS) t+ } \\
\text { Loneliness }\end{array}$ & $\begin{array}{l}0-10 \text { numeric scale } \\
0-10 \text { numeric scale } \\
0-10 \text { numeric scale }\end{array}$ \\
\hline NHS Usage & $\begin{array}{l}\text { Planned GP appointments in last } 6 \\
\text { months } \\
\text { Emergency GP appointments in last } 6 \\
\text { months } \\
\text { Planned hospital appointments in last } 6 \\
\text { months } \\
\text { Accident and Emergency attendances } \\
\text { in last } 6 \text { months } \\
\text { Nights in Hospital in last } 6 \text { months }\end{array}$ & $\begin{array}{l}\text { Frequency } \\
\text { Frequency } \\
\text { Frequency } \\
\text { Frequency } \\
\text { Frequency }\end{array}$ \\
\hline Falls & Number of falls in last 6 months & Frequency \\
\hline $\begin{array}{l}\text { Self-reported activity } \\
\text { and mobility ratings }\end{array}$ & $\begin{array}{l}\text { Activity rating } \\
\text { Mobility rating }\end{array}$ & $\begin{array}{l}0-10 \text { numeric scale } \\
0-10 \text { numeric scale }\end{array}$ \\
\hline Health Behaviours & $\begin{array}{l}\text { Completion of breast cancer tests } \\
\text { Completion of cervical cancer tests } \\
\text { Completion of bowel cancer tests } \\
\text { Smoking levels } \\
\text { Alcohol consumption } \\
\text { Completion of blood pressure test }\end{array}$ & $\begin{array}{l}\text { Binary (yes/no) } \\
\text { Binary (yes/no) } \\
\text { Binary (yes/no) } \\
5 \text { point Likert scale } \\
5 \text { point Likert scale } \\
\text { Binary (yes/no) }\end{array}$ \\
\hline
\end{tabular}

† For further information see [8] page 2. †† For further information see [9].

\subsection{Sample size}

The target sample size of 200 per group was calculated to be large enough to allow for a small effect size (0.25) to be picked up (alpha $=0.05$, power $=0.8$ ) including an allowance for attrition. At an attrition rate of $20 \%$ the sample size would remain sufficiently large. In the event a final sample size of 547 was obtained of which 15 were immediately moved into Group $3 \mathrm{~b}$ after the baseline health assessment. Of the remaining 532 participants, there were 186 in the control group (Group 1), 172 in the signposting group (Group 2) and 174 in the handholding group (Group 3). A further 10 were moved to Group3b at the interim assessment (see Section 2.1). 


\subsection{Randomisation}

The process of random number generation and assignment was carried out through an automated function in the data entry system. A restricted randomisation was used, with stratification by age (over and under 70) and gender. No blocking was used.

\subsection{Blinding}

Assessors were not told about the assignment group of participants, but those providing support (either the neighbourhood manager or support worker) necessarily were.

Towards the end of the study it was not always possible to maintain blind assessments since the assessors were in-house and so occasionally interacting with participants. Support workers occasionally carried out assessments, but never of their own clients.

Furthermore, during the process of assessment, discussion of the participant's health sometimes resulted in a disclosure of treatment (for example, if a participant referred to their support worker). This was primarily an issue for those in Group 3, whereas for those in Group 2 and the control group the intervention difference was less marked.

\subsection{Statistical methods}

ANOVA/Mixed ANOVA was used to analyse the between-group differences in mean baseline outcomes and improvements in these outcomes during the trial. Non-parametric ANOVAs (Kruskal-Wallis) were also run on variables where there were outliers as a check on the ANOVA results. The results of the Mixed ANOVAs are reported except for those cases - in particular outcomes relating to NHS usage - where there was evidence of outliers and a contradiction with non-parametric results. In these cases non parametric Kruskal Wallis tests are reported.

When handling categorical dependent variables, Chi-Square analysis was used with Phi and Cramer's $\mathrm{V}$ as an estimate of effect size.

\section{Results}

\subsection{Participants}

Overall, $77 \%$ of the original sample ${ }^{2}$ was retained through to the point of final assessment. The main cause of sample attrition - 64 cases - was the inability to make contact with participants to conduct their final assessment, a further 25 opted out, 12 left Family Mosaic accommodation and 14 died. The highest attrition rates were amongst the control group (52), followed by Group 2 (38) then Group 3 (25). However, a Chi-Square Analysis did not reveal any statistically significant differences in attrition rates between groups at the $5 \%$ level in terms of demography, gender or ethnicity.

\footnotetext{
${ }^{2}$ Excluding those moved to $3 b$
} 


\subsection{Recruitment}

Recruitment to the study began in January 2013 through a process of mail-outs, phone calls and door knocking. The first assessments were carried out in February 2013. Recruitment ended in February 2014 despite the sample still being a little below the target so as to ensure the study could be completed within a 3 year time frame.

The trial continued for a period of 29 months, with all final assessments completed by May 2015. The intended assessment timeframe was 18 months but because of unexpected difficulties with final assessments, some had to be carried out beyond the 18 month period. In order to minimise retention problems and ensure access to participants some assessments were brought forward. As a result of these adjustments, on average each participant was in the study for a period of 606 days (approx. 20 months). However, those receiving an intervention received it for only 18 months. The duration of participation was even across groups, with Group 1 and 3 participants being in the study for an average of 605 days and Group 2608 days.

\subsection{Sample characteristics}

The baseline health indicators for participants were compared to health ratings from Census 2011. As expected given the low income, social housing based sample, health indicators were worse for participants than for the population of London as a whole, though not always relative to their home Borough. Differences between participants and their Borough were more marked in the two most prosperous areas, Hammersmith and Fulham, and Chelsea and Kensington. Indicators from the 2007 Indices of Multiple Deprivation (IMD) show that participants lived in residential wards that were more deprived than their Boroughs in Haringey, Hammersmith and Fulham, and Kensington and Chelsea. The mean IMD score for participants in both Hackney and Islington was slightly better than the mean for their boroughs. Thus our participants were drawn from populations exhibiting low but not the lowest IMD and on average had health measures below, but not an order of magnitude below London's. Our study was dealing with deprived individuals but not the most deprived. Detailed results are shown in the supplementary Tables.

\subsection{Intervention and control group comparisons}

Analysis of the baseline data for the original 532 participants identified no statistically significant differences across the groups. Participants' average age was $64.3(\mathrm{p}=0.771$ for differences between groups), $66.6 \%$ were female $(p=0.854)$ and $67.8 \%$ were from non-white British ethnic groups $(\mathrm{p}=0.348)$.

A total of $94 \%$ of the original participants identified themselves as suffering from one or more long-term health conditions, with on average each suffering from three (excluding the 15 transferred to Group $3 \mathrm{~b}$ after their initial assessment). On average participants rated their health 'fair'. In a 6 month period all participants together had made a total of 2073 planned and 192 emergency visits to their GP, 1369 planned hospital appointments, 185 visits to A\&E and spent 528 nights in hospital. There were no significant differences between groups over a range of health indicators (see Table 2). 
Table 2: Averages on key health variables by groups

\begin{tabular}{|c|c|c|c|c|}
\hline & Group 1 & Group 2 & Group 3 & $\begin{array}{l}\text { Between groups } \\
\text { difference ( } p \\
\text { value) }\end{array}$ \\
\hline $\begin{array}{l}\text { No. long-term health conditions } \\
\text { S.E. }\end{array}$ & $\begin{array}{c}3.07 \\
(0.17)\end{array}$ & $\begin{array}{c}3.60 \\
(0.18)\end{array}$ & $\begin{array}{c}3.64 \\
(0.19)\end{array}$ & 0.960 \\
\hline General health rating & 3.56 & 3.07 & 3.20 & 0.462 \\
\hline SWEMWB rating $(35=\max )$ & 24.45 & 24.70 & 25.06 & 0.625 \\
\hline S.E. & $(0.39)$ & $(0.45)$ & $(0.42)$ & \\
\hline ONS wellbeing rating $(40=\max )$ & 22.51 & 22.70 & 22.63 & 0.933 \\
\hline S.E. & $(0.38)$ & $(0.43)$ & $(0.42)$ & \\
\hline Loneliness rating ( $5=$ not lonely) & 3.58 & 3.55 & 3.61 & 0.890 \\
\hline S.E. & $(0.09)$ & $(0.09)$ & $(0.09)$ & \\
\hline Planned GP appointments* & 3.52 & 4.22 & 3.98 & 0.226 \\
\hline S.E. & $(0.28)$ & $(0.35)$ & $(0.34)$ & \\
\hline Emergency GP appointments* & 0.45 & 0.24 & 0.38 & 0.182 \\
\hline S.E. & $(0.10)$ & $(0.06)$ & $(0.08)$ & \\
\hline Planned hospital appointments* & 1.98 & 2.59 & 3.18 & 0.253 \\
\hline S.E. & $(0.25)$ & $(0.35)$ & $(0.61)$ & \\
\hline A\&E attendances ${ }^{*}$ & 0.38 & 0.40 & 0.27 & 0.500 \\
\hline S.E. & $(0.08)$ & $(0.09)$ & $(0.07)$ & \\
\hline Nights in hospital & 0.94 & 1.19 & 0.85 & 0.286 \\
\hline S.E. & $(0.27)$ & $(0.41)$ & $(0.32)$ & \\
\hline Falls (in 6 months)* & 0.65 & 0.55 & 0.32 & 0.533 \\
\hline S.E. & $(0.14)$ & $(0.09)$ & $(0.06)$ & \\
\hline Activity levels (10= highly active) & 5.58 & 5.25 & 5.89 & 0.097 \\
\hline S.E. & $(0.20)$ & $(0.21)$ & $(0.19)$ & \\
\hline Mobility levels (10= highly mobile) & 6.98 & 6.61 & 7.36 & 0.230 \\
\hline S.E. & $(0.19)$ & $(0.20)$ & $(0.18)$ & \\
\hline Sample size & 186 & 172 & 174 & \\
\hline
\end{tabular}

* Mean in past 6 months.

\subsection{Numbers analysed}

Analysis was undertaken on two separate datasets. An as-treated (AT) analysis was conducted for all 408 participants who completed their time in the study. The group sample sizes were 133, 128 and 147 for Groups 1, 2 and 3 respectively. An intention-to-treat (ITT) analysis was conducted on an imputed dataset for the 532 participants with a valid first assessment (see Section 2.5 for sample sizes).

The ITT dataset was produced through multiple imputation, where missing data points were replaced with substituted values calculated through the expectation-maximisation (EM) algorithm. According to previous evaluations [10] this is the most reliable non-highly 
computing intensive method for generating ITT data sets. A Little's test was conducted and there was no evidence to suggest that data was not Missing Completely At Random (ChiSquare $=48182.277, \mathrm{DF}=49747, \mathrm{p}=1.000$ ). Some invalid data points were produced by the imputation (some slightly negative scores on the NHS usage for example) but on rounding to one decimal place virtually all negative values became zeros, and so this imputation was treated as valid. The outcomes reported below are estimated on the basis of the ITT analysis since this avoids problems of non-random attrition from the sample. For purposes of comparison, the results of the AT analysis are reported in Section 3.6.

\subsection{Final Outcomes}

This section summarises the findings of comparisons between the baseline and final assessment scores for each group on a range of indicators. The more significant results for NHS usage are shown in Table 3.

\section{Health ratings}

On self-reported health ratings, two measures were used; a general health rating out of five and an average health rating (out of 10) which was taken at the beginning and end of the survey. This latter score was calculated by taking an average of the two responses to the question.

There was a general, albeit slight (within 1 decimal point), improvement in scores across the groups but the ANOVA analysis identified no significant difference between groups (general health, $\mathrm{p}=0.674$, average health $\mathrm{p}=0.487$ ).

\section{Wellbeing indicators}

Short Warwick Edinburgh Mental Wellbeing (SWEMWB) Scale: Whilst Group 3 witnessed a slight improvement in their SWEMWB (+0.21), both Groups $1(-0.1)$ and $2(-0.9)$ experienced a decline. ANOVA analysis revealed a substantial interaction between study group and time $\left(F_{(2,529)}=2.593, p=0.076, n^{2}=0.01\right)$. Post-hoc analysis identified significant differences between Groups 2 and 3 ( $\mathrm{p}=0.019$ ) with Group 2's wellbeing being on average $1.5( \pm 1.3)$ points lower.

ONS Wellbeing Scale: There was a general decline in ONS scores across the groups, but we found no significant differences between groups for the ONS wellbeing measures, $\left(\mathrm{F}_{(2,525)}=\right.$ 1.029, $\left.\mathrm{p}=0.358, \mathrm{n}^{2}=0.004\right)$.

Loneliness and connections to community: There were slight but not statistically significant improvements in loneliness scores, but reductions in scores on connection to community were witnessed across all groups. The measures used for loneliness and social isolation are however less reliable indicators of wellbeing as they are not validated measures. ANOVA analysis revealed no significant differences for loneliness $\left(\mathrm{F}_{(2,525)}=0.717, \mathrm{p}=0.489, \mathrm{n}^{2}=0.003\right)$ or social isolation $\left(\mathrm{F}_{(2,525)}=1.10, \mathrm{p}=0.334, \mathrm{n}^{2}=0.004\right)$.

NHS usage

Analysis of the difference in usage of individual NHS services revealed three significant results. A Kruskal-Wallis test revealed significant differences for emergency GP visits, 
planned hospital appointments and nights in hospital. The overall findings are reported in Table 3.

Table 3: Baseline and Final Change in NHS Usage per Person and Kruskal-Wallis tests

\begin{tabular}{|l|c|c|c|c|c|}
\hline & $\begin{array}{c}\text { Planned GP } \\
\text { visits (\% } \\
\text { change) }\end{array}$ & $\begin{array}{c}\text { Emergency } \\
\text { GP visits } \\
\text { (\% change) }\end{array}$ & $\begin{array}{c}\text { Planned } \\
\text { Hospital } \\
\text { appointment } \\
\text { (\% change) }\end{array}$ & $\begin{array}{c}\text { AEE } \\
\text { attendances } \\
\text { (\% change) }\end{array}$ & $\begin{array}{c}\text { Nights in } \\
\text { Hospital } \\
\text { (\% change) }\end{array}$ \\
\hline Group 1 & 4.28 & 22.62 & 11.11 & -13.16 & 17.14 \\
Group 2 & 4.68 & 129.16 & -3.47 & -17.50 & -33.66 \\
Group 3 & -10.97 & -15.15 & -38.99 & 2.13 & -61.49 \\
\hline Kruskal-Wallis independent samples tests for differences between groups in change in NHS usage \\
\hline H statistic & 1.598 & 5.704 & 10.746 & 1.175 & 7.655 \\
p-value & 0.450 & 0.058 & 0.005 & 0.556 & 0.022 \\
\hline Kruskal-Wallis p-values for pairwise comparisons (outcomes with significant differences above) \\
\hline G2-G1 p-value
\end{tabular}

Group 3 reduced their usage of GPs for emergency visits by 15.1 percent (10 appointments) against Group 2's 124 percent increased usage (52 appointments). This reduction was statistically significant $(\mathrm{p}=0.045)$. The control group increased their visits by 23 percent (19 appointments) but this was not significantly different to Group 3. Group 2's usage was also not significantly different from that of the control group

On planned hospital appointments, Group 3's usage reduced (by 39\%, 216 appointments or 1.24 per person) while Group 1's usage increased (by 11\%, 41 appointments, 0.22 per person). This difference is significant $(p=0.004)$. Group 3 also reduced their usage by much more than Group 2 (where planned appointments fell by only 3.5\%, 16 appointments or 0.09 per person). Again the difference between Group 3 and Group 2 is significant $(p=0.065)$

Number of nights in hospital fell for Group 2 (by 33.7\% or 68 nights in total) while Group 1 increased their usage (by $17.1 \%$ or 30 nights), the difference being significant ( $p=0.022$ ). Although nights spent in hospital by Group 3 also fell (by $61.5 \%$ or 91 nights) the difference between Group 1 and Group 2 is non-significant, due to a high variance in the number of nights within Group 3 (20.217).

Absolute differences in outcomes on the other measures - number of falls per person, activity and mobility and preventative behaviour such as screening tests - were negligible and no differences between groups were significant.

As-treated analysis

An as-treated analysis was also carried out for comparison. Within the as-treated analysis the only outcome where significant differences were identified between the groups was for planned hospital appointments $\left(\mathrm{F}_{(2,391)}=5.366, \mathrm{p}=0.05\right)$ and SWEMWB scores $\left(\mathrm{F}_{(2,391)}=3.790\right.$, 
$p=0.023)$ although the signs and absolute values for other measures of NHS usage were similar to the ITT results.

\subsection{Group 3b}

In some ways the finding that in a randomly selected sample of social housing tenants aged over 50, some 4.5 percent had urgent - in most cases life-threatening but untreated health problems - is both the most interesting and most disturbing finding revealed by the study. All 25 in this group either had no GP or had no contact with any external medical help except for emergency visits to A\&E. Examples were a case of sickle cell anaemia who was not registered with a GP but went to A\&E when taken seriously ill or a recluse with serious heart problems who although registered with a GP only left the house once a week for basic shopping.

As Table 4 reveals there was an absolute improvement on every single measure following their assignments to the most intensively treated group, although these differences are not significant given the small sample size. ${ }^{3}$ There were improvements on wellbeing scores, self-reported health and activity/mobility ratings and reductions in all forms of NHS usage. As for the intensively treated group, Group 3, the most notable change in NHS usage was in planned hospital appointments, with a net reduction of 58 across the 25 participants. Other notable changes included the improvements in wellbeing, particularly on the ONS rating (increased average score by $7 \pm 1.9$ ).

Table 4: Mean differences for Group 3b

\begin{tabular}{|l|c|c|}
\hline & $\begin{array}{c}\text { Average change in } \\
\text { scores (over 18 months) }\end{array}$ & Standard Error \\
\hline General health & 0.4 & 0.2 \\
Planned GP appointments & -1.2 & 1.3 \\
Emergency GP appointments & -0.5 & 0.2 \\
Planned hospital appointments & -2.2 & 1.9 \\
A\&E attendances & -0.4 & 0.2 \\
Nights in hospital & -0.9 & 0.9 \\
ONS score & 6.6 & 1.9 \\
SWEMWB score & 1.0 & 1.6 \\
Loneliness score & 0.2 & 0.5 \\
Community connection score & 0.3 & 0.2 \\
Falls score & -0.5 & 0.7 \\
Activity score & 1.1 & 0.7 \\
Mobility score & 1.0 & 0.9 \\
\hline
\end{tabular}

\footnotetext{
${ }^{3}$ An alternative approach is simply to redo the analysis adding all the participants assigned to Group $3 b$ to an enlarged Group 3 - a Group containing all those provided with the most intensive intervention. This has the effect of increasing the significance of the differences in outcomes where there were already statistically significant differences but does not generate any additional significant outcomes.
} 


\subsection{Supplementary Analysis}

\section{Interventions}

The impact of different types of services and interventions was also assessed. The only significant results appear interestingly perverse. Holding group and other interventions constant, significant interactions were identified between information provision (such as the timetable for activities or healthy eating advice) and planned GP appointments. Those receiving information increased their GP attendances by an average of 2 visits within a 6 month period $(B=1.88, \mathrm{p}=0.027)$.

Significant interactions were also identified between attendance at activities (both those run by Family Mosaic and those available in the local community) and self-reported health ratings, with those attending activities reporting slightly lower levels of general health in their second assessment $(B=-0.369, p=0.005)$.

Both these apparently perverse results, however, are consistent with the observation discussed below in relation to 'harms' that raising expectations seemed to cause negative effects if those expectations could not be met.

\section{Harms}

The only significant adverse effect identified was for Group 2 on their SWEMWB score. Feedback from staff delivering the service for this group (who received only 'signposting') highlighted the difficulties in delivering health and wellbeing interventions, both in terms of time available and the limited involvement entailed. Signposting in isolation was judged not to be enough to translate into actual action, so participants may have felt frustrated by becoming aware of services which could potentially be helpful, but not feeling confident or able to actually take advantage of them.

Qualitative analysis of participants' comments at the end of the study supported this hypothesis. The main negative experiences reported were difficulties in attending activities (mainly due to timing or location) and that more support would have been beneficial. By contrast, this was infrequently mentioned by those in Group 3, suggesting that having a support worker helped to overcome these issues.

\section{Conclusions}

Our study builds on work reported in for example [11,12]. Its participants were drawn from the tenants aged over 50 living - apparently successfully - in decent social housing for which there was a substantial waiting list. A randomised controlled trial found that quite minor health interventions involving guidance from support workers generated improvements on a range of outcomes, and significant ones for the most intensively treated group related to NHS usage. In contrast, there was no evidence of a positive effect from the sign-posting intervention: even some indication that this intervention might have a negative impact on wellbeing.

An important question is whether these benefits outweigh the costs of the intervention. For the more intensively treated Groups, 3 and $3 b$, these were relatively high at $£ 2250$ per 
participant per year, but on an ongoing basis would be substantially lower. However, a full cost benefit analysis based on this trial is not feasible. On standard costings, using national values, the difference in NHS usage between the control group and intensively supported group implies annual savings of some $£ 760$ per person.[13]

Although a useful and easy to estimate indicator, this figure is not particularly helpful as a measure of benefits. It cannot be applied as either a guide to the cost effectiveness of the interventions or to their social value in terms of a benefit cost analysis. The figure does not represent a real resource saving since all NHS services are oversubscribed and the unused appointments and hospital beds would have been taken up by others. This would have produced a welfare gain for all those now able to be treated, or treated more quickly. In estimating benefits one would also need to add the value of the wellbeing and quality of life improvements for those in both Groups 3 and, particularly, Group 3b, both from not having to attend appointments or spend time in hospital but also from better health. Then on the cost side the estimate for the purposes of this experiment do not give a reliable guide to the costs that would be incurred if a social housing provider implemented a standard set of interventions comparable to the those offered to Group 3. To estimate those one would first have to separate out the specific costs of: a) the baseline health studies and b) the intensive handholding interventions provided: then one would have to estimate the likely far lower costs of providing these assessments and interventions on a routine basis; as well as the elimination of the costs of recruiting participants. Such a cost benefit analysis is beyond the scope of the study, so we cannot conclude that a policy based on our findings would necessarily provide a net social gain. We can conclude, however, that there were substantial and positive impacts on both efficiency in the use of NHS resources and on human health and wellbeing.

The participants' status on the Index of Multiple Deprivation or health indicators was below that of the London average and in most - but not all cases - below that of their borough averages. Although disadvantaged, however, they were far from representing the most vulnerable in society. Nevertheless a baseline health assessment revealed that 4.5 percent of them needed immediate health interventions. In many cases the participants with urgent health needs were either not registered with a GP or not on their GP's radar or that of any other support services. Some just attended A \& E when they had a health crisis; others were reclusive. This finding suggests not only a lack of co-ordination in health provision but the possibility of a useful role for social landlords to exploit the advantage of access their position gives them to act as agencies for improving the health of their tenants while saving significant National Health Service resources. This warrants further investigation.

A limitation of the study was the inability to access NHS patient data. Records had originally been expected to be provided in anonymised form but re-organisation of NHS records at the time of the study made this impossible, making it necessary to rely on selfreporting of hospital usage. There may also be concerns of sample selection, with those with greater subjective health needs being more likely to participate. This may be reflected in the difference between the responses to the initial scoping survey of 360 over 50s residents, where only $71 \%( \pm 4.97 \%)$ reported one or more long term health conditions, compared to 
$92 \%( \pm 2.27 \%)$ of the study sample. On other measures the sample was representative of the broader over 50 s general-needs London tenant population making the generalizability of the findings strong.

\section{What is already known on this subject}

Equal access to healthcare, whilst a central tenet of the NHS since its foundation, is difficult to achieve and more difficult to measure. Telephone surveys suggest that access in the UK is good by international standards but it is known that ethnic minorities, the socially disadvantaged and less educated have worse access to health care than other groups; and telephone surveys necessarily undersample those groups likely to have the worst access.

\section{What this study adds}

Using a social housing provider's data base this study tested whether simple interventions could improve tenants' health or welfare and reduce NHS use, employing a randomised controlled trial The sample was drawn from tenants over 50 years of age living in 'general needs accommodation'. While disadvantaged the participants did not represent the most disadvantaged. The study still found that 4.5 percent of the original sample was suffering from serious, in many cases life-threatening, health problems at initial assessment for which they were getting no effective treatment. This was because these participants were either not registered with the NHS or engaged with any official agency. The study found that simple interventions for the treated group improved health and welfare measures in non-significant ways and significantly reduced use of NHS resources. On standardised costings this reduction was worth some $£ 760$ per person.

\section{Policy implications}

Many people fall through the healthcare net. The access which social landlords have to a substantial number of such vulnerable people places them in a position to reach them and provide simple health interventions. This has important policy implications since these interventions identified and helped to treat 4.5 percent of the study participants who had critical but untreated health issues; and while they achieved only non-significant improvements on health and well-being measures, the interventions saved a significant amount of NHS resources.

\section{Funding}

Family Mosaic provided resources directly and access to data. The five London Boroughs also provided some inputs. The time of Professors Cheshire and Gibbons was funded by the ESRC and Family Mosaic.

\section{Competing interests}

None declared.

\section{Patient consent}

Not relevant. Family Mosaic's participating tenants signed consent forms. 


\section{Ethics approval}

A detailed research plan was submitted to and approved by the Ethics Committee of the London School of Economics.

\section{Provenance and peer review}

Not commissioned: study originated in discussions between Mr John Schofield, Group Director of Family Mosaic, and Professors Cheshire and Gibbons, members of Family Mosaic's Innovation Panel.

\section{References}

[1] Osborn R, Squires D, Doty MM, Sarnak DO, Schneider EC. In New Survey of 11 Countries, U.S. Adults Still Struggle with Access to and Affordability of Health Care, Health Affairs Web First, published online Nov. 16, 2016

[2] Jones AM, Wildman J. Health, income and relative deprivation: Evidence from the BHPS. Journal of Health Economics. 2008 Mar; 27(2):308-24. doi: 10.1016/j.jhealeco.2007.05.007. Epub 2007 Dec 4.

[3] Benzeval M, Bond L, Campbell M, Egan M, Lorenc T, Petticrew, M et al. How Does Money Influence Health? Joseph Rowntree Foundation, York; 2014

[4] Cheshire PC, Nathan MA, Overman, HG. Urban Economics and Urban Policy: Challenging Conventional Policy Wisdom. Cheltenham: Edward Elgar; 2014.

[5] Marmot M. Fair Society, Healthy Lives. Strategic review of health inequalities in England post-2010. Department for International Development: 2010; ISBN 9780956487001

[6] See https://www.peabody.org.uk/about-us/who-we-are/our-heritage/peabody-throughthe-ages

[7] Bengtsson-Tops A, Hansson L. Landlords' experiences of housing tenants suffering from severe mental illness: a Swedish empirical study. Community Mental Health Journal. 2014 Jan. 50(1):111-19. doi: 10.1007/s10597-013-9596-4.

[8] Office for National Statistics. Personal Well-being in the UK, 2012/13. Statistical Bulletin. 2013;http://webarchive.nationalarchives.gov.uk/20160106062345/http://www.ons.gov.uk/ons /rel/wellbeing/measuring-national-well-being/personal-well-being-in-the-uk--2012-13/sb--personal-well-being-in-the-uk--2012-13.html

[9] Health Scotland. The Warwick-Edinburgh Mental Well-being Scale (WEMWBS). 2006.

[10] Blankers M, Koeter MWJ, Schippers GM. Missing Data Approaches in eHealth Research: Simulation Study and a Tutorial for Nonmathematically Inclined Researchers. J Med Internet Res. 2010 Oct-Dec; 12(5): [Available online at: doi: 10.2196/jmir.1448 
[11] Bardsley M, Steventon A, Smith J, Dixon J. Evaluating Integrated and CommunityBased Centre: How do we know what works? Nuffield Trust; 2013. [Available online at: https://www.nuffieldtrust.org.uk/research/evaluating-integrated-and-community-basedcare-how-do-we-know-what-works, accessed $1^{\text {st }}$ March 2017]

[12] Elkan R, Kendrick D, Dewey M, Hewitt M, Robinson J, Blair M, et al. Effectiveness of home based support for older people: systematic review and meta-analysis. BMJ : British Medical Journal. 2001 323(7315):719.

[13] DoH (Department of Health). NHS Reference Costs 2013 to 2014. 2014; https://www.gov.uk/government/publications/nhs-reference-costs-2013-to-2014. 